\title{
Influence of emotions on digital learning
}

\author{
Kausalai (Kay) Wijekumar ${ }^{1}$
}

Accepted: 14 January 2021 / Published online: 23 February 2021

(c) Association for Educational Communications and Technology 2021

\begin{abstract}
Emotions have been theoretically and empirically linked to engagement and learning outcomes in many domains and settings. A recent quasi-experimental study measured medical students' emotions after completing four diagnostic tasks in a computer based learning environment (Jarrell et al., Educ Technol Res Dev 65:1263-1284, 2017). Cluster Analysis showed three distinct groups and students in the positive emotion cluster performed well on their diagnostic tasks and negative emotions were linked to poor performance. Three perspectives about the results are presented in this Special Issue: K-12 teacher and administrator, student, and practical and policy. All perspectives focus on the need for additional research in the area of emotions and digital learning. Recommendations for future research are presented with a need for causal studies that meet the What Works Clearinghouse Guidelines.
\end{abstract}

Keywords Emotions · Digital Learning $\cdot$ Motivation

Strong empirical research on how emotions influence engagement in computer-based learning environments (CBLE) has the potential to inform and guide the development and delivery of instruction in all modalities, including digital platforms. An exploratory correlational study by Jarrell et al. (2017) presented in this Special Issue adopts a strong theoretical framework, control value theory of achievement emotions, a consequential area of medical learning using CBLEs and performance feedback, and reports on three different emotional clusters impacting diagnostic skills: (a) positive emotion, (b) negative emotion, and (c) low-intensity motivation. This Special Issue presents perspectives from k-12 teacher and administrator, student, and theory and policy foci to explore the use of Jarrell and colleagues' research study to inform the shift to digital learning.

Many domains and settings have theoretically and empirically linked emotions to engagement and learning outcomes (Linnenbrink-Garcia and Pekrun 2011; Pekrun et al. 2011). The unusual circumstances surrounding the recent shift to digital learning have brought more attention to the need to explore and address the impact of emotions in these settings. Jarrell et al. (2017) conducted a study to correlate emotions to medical students' performance on medical diagnoses within CBLEs. Using retrospective data collected about

Kausalai (Kay) Wijekumar

K_Wijekumar@tamu.edu

1 Texas A\&M University, 420C Harrington Tower, College Station, TX 77843, USA 
emotions and performance on four diagnostic tasks, the authors conducted a k-means cluster analysis that revealed three distinct clusters of emotions that correlated with the learners' diagnostic outcomes. Medical student participants classified in the positive emotion cluster had the highest performance, students reporting negative affect had the lowest performance, and students in the low-intensity cluster performed moderately well on the diagnostic measures.

These results provide a sound foundation to further explore whether these emotions are (a) malleable factors that can be harnessed in support of engagement, persistence, and achievement, (b) impactful in other areas of interest, including teacher implementation of digital tools and student outcomes in other learning environments (e.g., K-12 students learning on digital platforms), and (c) refined and re-purposed through intervention. If these avenues are explored, emotions may be harnessed effectively to shape motivation to learn, engagement with the learning systems, persistence in overcoming challenges, and performance on tests and other consequential capstone activities.

The first perspective presented by Owens and Hudson (this issue) suggests that this research may serve as a model to study teacher and administrator emotions in K-12 settings. They report on research about teachers and administrators working in high demand and low control settings, resulting in emotional exhaustion, increased teacher turnover, and decreased teaching performance. Focusing on emotions as a malleable factor, they suggest developing and testing interventions and teacher reflective practices to harness necessary emotions. The burden of shifting to digital learning has been borne primarily by K-12 teachers and administrators; thus, applying emotion-related research to those settings can inform the field of educational technology.

A K-12 student perspective presented by Moore (this issue) focuses on new legislation and emphasis on evidence-based social-emotional learning practices for students, shifting from a classroom setting where teachers can see and react to student needs to digital platforms where such engagement may be limited - thereby, highlighting the need to measure and respond to student emotions in digital platforms continuously. Moore also focuses on interventions that may promote mindfulness and emotional awareness and longitudinal studies that can explore young learners' shift to digital learning. Finally, she suggests a need to study the K-12 student audience before utilizing knowledge gained from Jarrell et al.'s study with medical students who are likely high performing and motivated.

$\mathrm{Ge}$ (this issue) presents the final perspective on the practical and policy impact of this research. She notes that teachers and students shifting rapidly to digital learning may experience negative emotions and suggests multiple extensions to this study. First, developing and testing strategies to foster positive emotions. Second, supporting students with selfregulatory skills that can reduce the negative emotions. Finally, the need for emotional supports for students are presented. Multiple data collection methods to measure emotions and additional research are also recommended.

The findings from the Jarrell et al. study combined with the three perspectives presented encourage researchers to explore further the complex construct of emotion, conditions under which emotions emerge, interventions that can promote the mindful control of emotions, and how emotions can be harnessed to promote engagement, persistence, learning, and performance outcomes. Robust research designs that allow the field to draw causal conclusions (e.g., What Works Clearinghouse Guide 2020) are recommended to support future progress related to digital learning. These research designs include strong theoretical foundations for the intervention design, randomized controlled trials with appropriate 
samples, replication of findings in different settings to inform generalizability, reliable and valid measures, and careful data analyses to draw causal conclusions.

\section{References}

Jarrell, A., Harley, J. M., Lajoie, S., \& Naismith, L. (2017). Success, failure and emotions: Examining the relationship between performance feedback and emotions in diagnostic reasoning. Educational Technology \& Research Development, 65, 1263-1284 (2017). https://doi.org/10.1007/s11423-017-9521-6.

Linnenbrink-Garcia, L., \& Pekrun, R. (2011). Students' emotions and academic engagement: Introduction to the special issue. Contemporary Educational Psychology, 36(1), 1-3, ISSN 0361-476X. https://doi. org/10.1016/j.cedpsych.2010.11.004.

Pekrun, R., Goetz, T., Frenzel, A. C., Barchfeld, P., \& Perry, R. P. (2011). Measuring emotions in students' learning and performance: The achievement emotions questionnaire (AEQ). Contemporary Educational Psychology, 36(1), 36-48, ISSN 0361-476X. https://doi.org/10.1016/j.cedpsych.2010.10.002.

What Works Clearinghouse (2020, November 16). What works clearinghouse ${ }^{\mathrm{TM}}$ Standards Handbook Version 4. https://ies.ed.gov/ncee/wwc/Docs/referenceresources/wwc_standards_handbook_v4.pdf.

Publisher's Note Springer Nature remains neutral with regard to jurisdictional claims in published maps and institutional affiliations.

Kausalai (Kay) Wijekumar is Houston Endowed Chair and Chancellor's EDGES Fellow at Texas A\&M University, College Station. She has dedicated her life to developing, testing, and deploying powerful digital learning systems to improve learning. Her recent research focuses on improving reading and writing in K-12 schools using web-based intelligent tutoring systems. She has also extended the intelligent tutors to provide teacher practice based professional development. 